\title{
Human Capital Management, Organizational Climate, Commitment and Performance in Latin America
}

\author{
Emmanuel Silvestre ${ }^{1 *}$, Fernando Toro ${ }^{2}$, Alejandro Sanin ${ }^{2}$ \\ ${ }^{1}$ Research Department, ISFODOSU, Santo Domingo, Dominican Republic \\ ${ }^{2}$ Cincel, Medellín, Colombia \\ Email: *esilvestre@esilvestre.com
}

How to cite this paper: Silvestre, E., Toro, F., \& Sanin, A. (2018). Human Capital Management, Organizational Climate, Commitment and Performance in Latin America. Psychology, 9, 34-45. https://doi.org/10.4236/psych.2018.91003

Received: December 6, 2017

Accepted: January 8, 2018

Published: January 11, 2018

Copyright ( $) 2018$ by authors and Scientific Research Publishing Inc. This work is licensed under the Creative Commons Attribution International License (CC BY 4.0).

http://creativecommons.org/licenses/by/4.0/

\section{c) (i) Open Access}

\begin{abstract}
The purpose of the research was to confirm the validity of an analytical model originally proposed by Kopelman, Brief and Guzzo (1990) in 4 countries of the Latin American region. Cincel, a top organizational research institution from Colombia, adapted the original model and coordinated this research. The objectives of the research included to make various comparisons and relationships among some productive sectors and countries of the region. Cincel's analytical model implies that the Human Capital Management Practices (HCMP) can predict the Perceived Organizational Performance (POP), but also that this relationship is moderated by the variables Organizational Climate (OC) and, at minimum, 3 types of commitment of the staff: Affective Commitment (AC), Continuity Commitment (CC) and Normative Commitment (NC). The research includes a total sample of 4491 participants from Chile (CL), $\mathrm{N}=799$, Colombia (CO), $\mathrm{N}=2083$, Mexico (MX), $\mathrm{N}=874$, and the Dominican Republic (DO), $N=735$. The productive sectors included were Industry, Services and Education. The instruments for the data gathering were supplied by Cincel. The questionnaires were administered via Internet by Cincel. The moderation analysis was done with the regression procedure of the SPSS. In general, the moderation analysis validated the model, with important differences for the included sectors. HCMP and OC were effective in predicting POP in every sector. AC was a good predictor of POP in the Services and Education sectors, while CC could only predict POP in the Education sector and the NC was a good predictor of POP only in the Industry sector. The interaction between $\mathrm{OC}$ and $\mathrm{CN}$ was able to predict POP in both the Industry and Services sectors. Furthermore, we found significant differences, confirmed by ANOVAS, among the evaluations in the different countries. CO performed better in the evaluations in almost every factor for each sector. DO
\end{abstract}


was second in the evaluations of the Industry and Services sectors. MX was second in the Education sector, and CL was third in the Services sector. The human capital managers from each country should take in account the fact that the predictors of performance and the staff commitment are different for each country and for the different productive sectors.

\section{Keywords}

Human Capital Management Practices, Organizational Climate, Organizational Commitment, Perceived Organizational Performance, Human Capital in Latin America

\section{Introduction}

This research is part of an international study coordinated by the Center for Research in Organizational Behavior (CINCEL), a leader on organizational research from Medellin, CO. It is directed to confirm, for several countries in Latin America, an Analytical Model based on the model of Climate, Culture and Productivity by Kopelman, Brief \& Guzzo (1990).

The research included participants from large organizations from CL, CO, MX and the DO. These organizations came from the Industry, Services and Education sectors. In this paper, we try to integrate the results from the different sectors. The detailed results from each sector are published elsewhere or submitted for publication (Silvestre, Cruz, \& Sanín, 2016; Silvestre, Toro, \& Sanín, 2016; Silvestre, Toro, \& Sanín, unpublished).

HCMPs have been strongly and positively related to organizational performance, but this relationship is moderated by the type of measure used and the specific type of HCMP (Kehoe \& Wright, 2010). The relationship appears stronger when performance is measured by indicators of operational performance (for example, satisfaction with customer service or innovation), as opposed to measures of overall performance (for example, return on assets or returns in sales) (Jiang, Lepak, Hu, \& Baer, 2012).

In recent years, scholars and practitioners have increasingly recognized the importance of effective human capital management for the performance of the organization (Crook, Combs, Tood, Woehr, \& Ketchen, 2011). Practices that improve employee engagement and attitudes, improve indeed many financial performance indicators at work.

Several works by Toro $(2009 \mathrm{a}, 2009 \mathrm{~b})$ showed that the CO is a condition that produces significant effects on commitment. Toro (1998) also suggests that culture in general, and administrative practices in particular, decisively affect the climate of work teams and organizations.

According to the analytical model established by CINCEL as the basis for this study, the human capital or personnel management practices would provoke 
different perceptions of the reality of work and organization, producing different levels of organizational commitment to the work. In addition, the climate would be a moderator between such practices and commitment, but this commitment would be the most influential element on the organization's productivity. These relationships are depicted in Figure 1 which shows a summary diagram of the relationships between the dimensions of the model, since some of them have, in turn, several components. For example, HCMP can be divided into two sub-dimensions: Performance Orientation (PO) and Personnel Conservation Orientation (PCO). In the same way, different types of commitment have been proposed, the AC, the $\mathrm{CC}$ and the NC among them. We describe these components in the subsection 3.2.

The validity of this general model in different Latin American countries would imply structural similarities between them, which would agree with Hofstede's (1977) position. This researcher in the field of culture of the organization has reported great affinities in different regions of the world, including Latin America (LA), regarding administrative and management environments of productive organizations in each region.

However, especially in LA, the different countries have had their own political and economic histories, as well as very different customs and habits, which would allow finding particularities in the internal dynamics and the performance of their respective organizations.

\section{Objectives}

\subsection{Validation of the Analytical Model}

To validate the Analytical Model proposed by CINCEL by determining the weight of its different dimensions when influencing one another.

\subsection{Similarities and Differences among Countries}

We also tried to verify the similarities and differences among the participating countries, with respect to the evaluations of the dimensions of the Model.

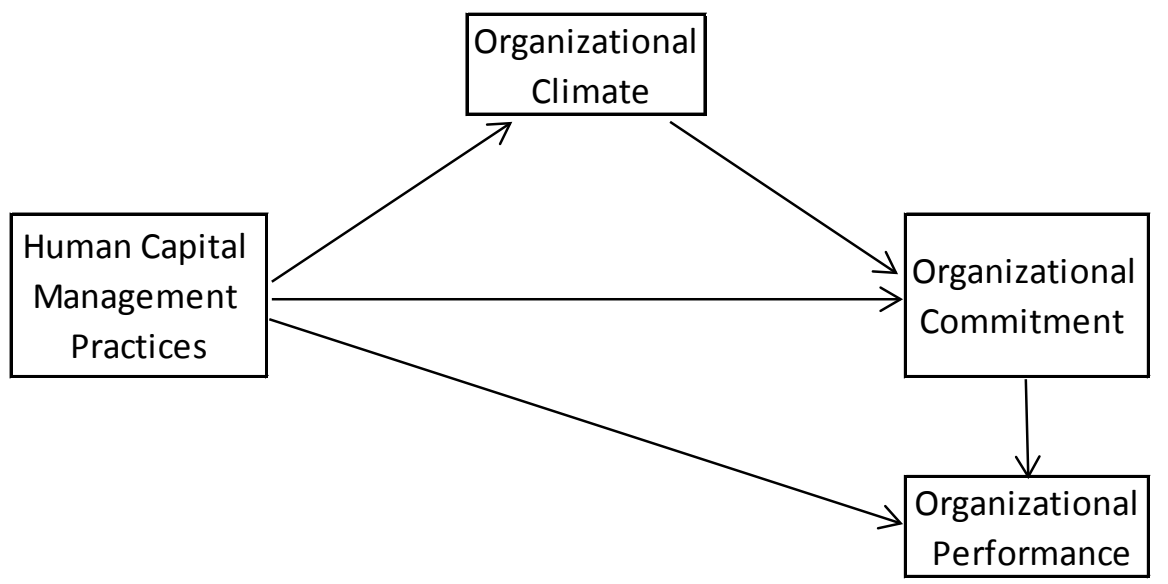

Figure 1. Analytical Model proposed by CINCEL, Source: CINCEL, p. 4 [unpublished]. 


\section{Method}

\subsection{Participants}

Table 1 shows the number of participants in the research by country and productive sector.

We selected our sample by availability. The participants were selected randomly, but keeping their stratification according to the proportions of employee category, education, gender, department and seniority in their respective organizations. From CL we had 1 industry, 3 services companies and 1 university. From CO, 4 industries, 5 services companies and 4 universities. From MX, 2 industries, 2 services companies and 3 universities. From DO we had 2 industries, 2 services companies and 1 university. As can be seen on Table 1, the total sample was 4490 participants.

\subsection{Instruments and Variables}

CINCEL provided all the measurement instruments. To measure HCMP we use an adaptation of the scale used by Gong, Law, Chang \& Xin (2009). Items were answered on a 4-point Likert-type scales described as: (1) Strongly Disagree, (2) Disagree, (3) Agree, and (4) Strongly Agree. A value of (0) was added for the option Neither Agree, Neither Disagree. The midpoint of the scale was eliminated to avoid the central tendency error. The psychometric indicators of the scale can be found in Toro, Sanín and Guevara (2013).

This scale included perceptions of performance evaluation, training, and personnel selection, which make up the PO sub-dimension. We also evaluated stability in employment, reduction of status differences, participation in decision making and compensation contingent with performance. These factors compose the SCO sub-dimension. The average of all these measures constituted the HCMP dimension.

The OC is understood as the perception or representation of the realities of the work, not as the opinion about those realities or as the attitude toward them or as the satisfaction with them. The OC is a way of seeing the reality shared by the people of a company (Toro, 2000). To measure OC we used the Reduced ECO IV scale, built and validated by Toro (1992). This scale includes 9 factors:

Table 1. Participants by country and productive sector.

\begin{tabular}{ccccc}
\hline \multirow{2}{*}{ Countries } & \multicolumn{4}{c}{ Productive Sectors } \\
\cline { 2 - 5 } & Industry & Services & Education & Totals \\
\hline Chile & 39 & 628 & 132 & 799 \\
Colombia & 503 & 830 & 749 & 2082 \\
Mexico & 488 & 137 & 249 & 874 \\
Dominican Republic & 293 & 220 & 222 & 735 \\
Totals & 1323 & 1815 & 1352 & 4490 \\
\hline
\end{tabular}


Stability, Interpersonal Relationships, Sense of Belonging, Coherence, Teamwork, Organizational Clarity, Availability of Resources, Boss Support and Retribution.

Organizational Commitment is the degree to which an employee identifies himself with an organization and its goals, and wishes to maintain this relationship. There is quite a consensus with the model of Meyer and Allen (1991) that raises three dimensions of commitment:

1) AC. This is the emotional attachment of the employee with the company and is acquired if the organization meets the needs and expectations of the worker.

2) CC. This occurs as a result of the time and effort that the person has invested on his stay in the company and would lose if he leaves his position.

3) NC. This comes from the moral duty or gratitude felt by the worker when he believes that he must respond reciprocally to the company as a result of the benefits obtained (treatment, training, labor improvements, etc.).

The POP was registered with measures of operational performance through items that asked the participant to compare the company in the last 3 years in relation to how product quality was perceived, the development of new products, the acquisition and retention of qualified employees, customer satisfaction and relationships between employees and supervisors.

\subsection{Procedure}

The surveys were administered directly by CINCEL through the Internet and also in person. CINCEL then provided the databases to researchers in each country so that they could present the results to participating companies.

In each company, authorization was requested from human management personnel to allow staff participation. Additionally, each person was asked for their informed consent. CINCEL's Scientific Committee endorsed the research after reviewing the technical, methodological and ethical aspects.

\subsection{Data Analysis}

The theoretical model of CINCEL was put to the test with a moderation analysis, which simultaneously compares the influence of independent variables and their interactions, on the dependent variable. To run the analysis we used the regression procedures from the SPSS, version 22.

The POP was placed as a dependent variable. The HCMP was included as an independent variable, as well as the others that would be also moderators: CO, $\mathrm{CA}, \mathrm{CC}$ and $\mathrm{CN}$.

The following interactions were included as moderating variables: $\mathrm{CO}{ }^{*} \mathrm{CA}$, $\mathrm{CO}{ }^{*} \mathrm{CC}$ and $\mathrm{CO}{ }^{*} \mathrm{CN}$.

As the sub-dimensions of HCMP, PO and SCO, contribute to this dimension, they were not included in this moderation analysis to avoid problems of collinearity. 
Nevertheless, we included the sub-dimensions of HCMP, PO and SCO, in the analysis of the differences between the countries, as in the analysis of variance (ANOVA) the collinearity is not an issue. With the SPSS we run 8 ANOVAs, one for each dimension and sub-dimensions of the model as dependent variables. For theses ANOVAs the independent variable was always the country: $\mathrm{CL}, \mathrm{CO}, \mathrm{MX}$ and DO.

\section{Results}

\subsection{Validation of the Proposed Analytical Model}

On Table 2 we show a summary of the moderation analysis for the sectors included in the research. The first column in Table 2 includes the number of the model computed in the regression. On the second column we find the constants and independent and moderator variables for the 2 regression models. The next three columns contain the statistics for the Industry sector on each factor: the standardized Beta coefficients $(\beta)$, the $t$ test and its statistical significance $(p)$. The next six columns show the same statistics for the Services and Education sectors.

Table 2. Summary of the moderation analysis for the industry, services and education sectors.

\begin{tabular}{|c|c|c|c|c|c|c|c|c|c|c|}
\hline \multirow{3}{*}{ Model } & \multicolumn{10}{|c|}{ Productive Sectors } \\
\hline & \multirow[t]{2}{*}{ Factors $^{\star}$} & \multicolumn{3}{|c|}{ Industry } & \multicolumn{3}{|c|}{ Services } & \multicolumn{3}{|c|}{ Education } \\
\hline & & Beta & $\mathrm{t}$ & Sig. & Beta & $\mathrm{t}$ & Sig. & Beta & $\mathrm{t}$ & Sig. \\
\hline \multirow[t]{6}{*}{1} & (Constant) & & .048 & .962 & & .301 & .763 & & .249 & .803 \\
\hline & $\begin{array}{l}\text { Zscore: } \\
\text { HCMP }\end{array}$ & .373 & 11.092 & .000 & .327 & 11.535 & .000 & .252 & 7.327 & .000 \\
\hline & Zscore: OC & .316 & 9.094 & .000 & .212 & 6.818 & .000 & .315 & 8.703 & .000 \\
\hline & Zscore: AC & -.038 & -1.545 & .123 & .225 & 6.805 & .000 & .164 & 4.751 & .000 \\
\hline & Zscore: CC & -.021 & -.92 & .358 & -.01 & -.454 & .65 & .051 & 2.242 & .025 \\
\hline & Zscore: NC & .193 & 7.943 & .000 & .038 & 1.315 & .189 & .035 & 1.140 & .255 \\
\hline \multirow[t]{9}{*}{2} & (Constant) & & .283 & .777 & & -1.111 & .267 & & -.980 & .327 \\
\hline & $\begin{array}{l}\text { Zscore: } \\
\text { HCMP }\end{array}$ & .371 & 10.949 & .000 & .314 & 11.063 & .000 & .256 & 7.457 & .000 \\
\hline & Zscore: OC & .315 & 8.945 & .000 & .221 & 7.105 & .000 & .310 & 8.582 & .000 \\
\hline & Zscore: AC & -.036 & -1.417 & .157 & .248 & 7.124 & .000 & .181 & 4.851 & .000 \\
\hline & Zscore: CC & -.025 & -1.061 & .289 & -.02 & -.872 & .383 & .043 & 1.853 & .064 \\
\hline & Zscore: NC & .187 & 7.656 & .000 & .041 & 1.412 & .158 & .041 & 1.328 & .184 \\
\hline & $\begin{array}{c}\text { Moderator } \\
\mathrm{OC}^{*} \mathrm{AC}\end{array}$ & .032 & 1.118 & .264 & -.06 & -1.409 & .159 & -.026 & -.664 & .507 \\
\hline & $\begin{array}{l}\text { Moderator } \\
\mathrm{OC}^{\star} \mathrm{CC}\end{array}$ & .042 & 1.56 & .119 & .037 & 1.528 & .127 & .035 & 1.380 & .168 \\
\hline & $\begin{array}{c}\text { Moderator } \\
\mathrm{OC}^{\star} \mathrm{NC}\end{array}$ & -.083 & -2.615 & .009 & .091 & 2.350 & .019 & .060 & 1.602 & .109 \\
\hline
\end{tabular}

Note: ${ }^{*}$ Dependent Variable: POP. 


\subsubsection{Predictors of POP in the Industry Sector}

In the Industry sector, model 1 without moderating variables, explains almost $55 \%$ of the variance of the DOP (Adjusted R2 $=.546$ ) and model 2, which includes the moderating variables, explains only a little more of that variance (Adjusted $\mathrm{R} 2=.547)$. Thus, the change implied by the inclusion of these moderating variables was minimal and not significant $(\mathrm{R} 2$ Change $=.003, \mathrm{p}=.073)$.

The analysis of variance for model 1 showed high significance, $F(5,1240)=$ $300.46, \mathrm{p}=.000$, as for model $2, \mathrm{~F}(8,1237)=189.26, \mathrm{p}=.000$. In both cases the effect size was enormous $(\mathrm{f} 2=1.22)$ and the power perfect ( 1 ).

In Table 2 for the Industry sector we see that, both in the regression model 1 and in model 2, the HCMP, the OC and the NC significantly influenced the POP. According to the $\beta$ coefficients, in model 2, a change of one deviation in the HCMP would produce a change of .371 deviations in the POP. Also in model 2 , a change of one deviation in the OC would produce a change of .315 deviations in the POP. The influence of the NC is practically half of the above because a change of one deviation on the NC would produce only a change of .187 deviations in the POP.

As a moderating variable, the interaction between $\mathrm{OC}$ and $\mathrm{NC}$ shows an inverse relationship with the POP since the value of $\beta$ is negative and, although small, it is statistically significant.

\subsubsection{Predictors of POP in the Services Sector}

In the Services sector, the importance of the 2 computed regression models was almost as high as in the Industry sector, as both of them explained more than half of the POP variance. Model 1 showed an Adjusted R2 $=.515$ and model 2, with the moderator variables interactions, showed an Adjusted R2 $=.519$. Nonetheless, although the inclusion of the moderator variables produced just a slight change, this was statistically significant ( 2 Change $=.005, \mathrm{p}=.000)$ and we had to accept the greater predictive power of model 2 .

The ANOVA for model 2 had a high statistical significance, $F(8,1718)=$ $233.697, \mathrm{p}=.000$, a very large effect size $(\mathrm{f} 2=1.079)$ and a perfect power $(1)$.

In Table 2 for the Services sector, according to the $\beta$ coefficients, in both models 1 and 2 the best predictors for the POP were, in that order, HCMP, AC, and OC. Model 2 gives a better prediction of the POP because it includes the OC by NC interaction. As shown on the $\beta$ coefficients in model 2, a change of one deviation on HCMP will produce a change of .314 deviations on the POP. The same change on AC will produce a change of .248 deviations on the POP. Consequently, if the OC changes one deviation the POP will change in .221 deviations. The inclusion of the OC by NC interaction in model 2 showed a small, but significant, predictive influence on the POP $(\beta=.091, \mathrm{p}=.019)$.

\subsubsection{Predictors of POP in the Education Sector}

In the Education sector, the importance of the 2 regression models was as important as in the two other sectors, explaining more than half of the POP variance. 
Model 1 had an Adjusted R2 $=.51$ and model 2 had an Adjusted R2 = .513. The change produced by the inclusion of the moderator variables in model 2 was small (R2 Change $=.004)$ but statistically significant (Sig. F Change $=.012$ ).

The ANOVA for model 2 also had a high statistical significance, $F(8,1279)=$ $170.236, \mathrm{p}=.000$, with a very high effect size ( $\mathrm{f} 2=1.07)$ and a perfect power $(1)$. According to the $\beta$ coefficients in Table 2 for the Education sector, in both models 1 and 2, the best predictor for the POP was OC, then HCMP, and AC. In model 2 a change of one deviation in OC would produce a change of .31 deviations on POP. The same amount of change in HCMP will change POP in .256 deviations. A change of one deviation on AC would change POP in .181 deviations.

Although CC was a significant predictor for POP in model 1, it did not reach statistical significance in model 2. The interactions among the moderating variables showed no significant predictions of the POP.

\subsection{Differences among Countries}

\subsubsection{Differences in the Industry Sector}

The differences among the countries showed the relative importance of the factors for each one of them. All factors obtained different evaluations in almost all the included countries. In Table 3 we can find the summary of the ANOVAs results for the Industry sector.

In the first column on Table 3, we can find the factors included in the research, the second column shows the F statistic for each factor, as its statistical significance in the third column. The fourth column contains the effect size (f) of each of the differences found for each factor, which were all large except for $\mathrm{CC}$, which was medium. In the fifth column we can see the power of each analysis, which was always very high. The last column shows the results of the post hoc multiple comparisons, which confirmed the differences among the countries at least at the .05 level of significance, using the Tamhane correction.

Table 3. Summary of the ANOVAs for the Industry sector among the countries.

\begin{tabular}{cccccc}
\hline \multirow{2}{*}{ Factors } & \multicolumn{5}{c}{ Industry Sector } \\
\cline { 2 - 5 } & F & Sig. & Effect Size (f) & Power & Multiple Comparisons \\
\hline POP & 96.231 & .000 & .43 & .95 & DO $>$ CO $>$ MX $>$ CL \\
HCMP & 76.176 & .000 & .39 & .95 & CO $=$ DO $>$ MX $>$ CL \\
PO & 76.506 & .000 & .39 & .96 & CO $=$ DO $>$ MX $>$ CL \\
SCO & 70.148 & .000 & .37 & .96 & $\mathrm{CO}=\mathrm{DO}>\mathrm{MX}>\mathrm{CL}$ \\
OC & 63.815 & .000 & .36 & .95 & $\mathrm{CO}=\mathrm{DO}>\mathrm{MX}>\mathrm{CL}$ \\
NC & 59.306 & .000 & .35 & .95 & $\mathrm{DO}>\mathrm{CO}>\mathrm{MX}>\mathrm{CL}$ \\
AC & 51.632 & .000 & .33 & .95 & $\mathrm{CO}>\mathrm{MX}>\mathrm{DO}>\mathrm{CL}$ \\
CC & 11.718 & .000 & .17 & .95 & $\mathrm{CO}=\mathrm{DO}>\mathrm{MX}>\mathrm{CL}$
\end{tabular}


The results in Table 3 were ordered by the size of the effect size. In the Industry sector the highest evaluations were for the POP, followed by the HCMP and the PO. The lowest evaluations were for the commitments: CC, AC, and NC.

In the Industry sector, five of the factors, HCMP, PO, SCO, OC and CC, were best evaluated by CO and DO, followed by MX and CL. DO made the highest evaluations for POP and NC, and CO made the highest evaluations for AC, followed by MX.

\subsubsection{Differences in the Services Sector}

In the Services sector the best evaluations were for $\mathrm{AC}$, followed by $\mathrm{OC}$ and POP. The lowest evaluations were for CC, SCO and HCMP. All effect sizes were large and the power of the analysis was always perfect.

In this sector, half of the factors, AC, POP, NC and CC, were best evaluated by CO, followed by DO, then CL and then MX. For the other factors, OC, PO, HCMP and SCO, the evaluations by CO and DO were equally high. A summary of these differences can be found in Table 4 .

\subsubsection{Differences in the Education Sector}

A summary of the differences in the evaluations of the included factors by the different countries can be found in Table 5 .

Table 4. Summary of the ANOVAs for the Services sector among the countries.

\begin{tabular}{cccccc}
\hline \multirow{2}{*}{ Factors } & \multicolumn{5}{c}{ Services Sector } \\
\cline { 2 - 6 } & F & Sig. & Effect Size (f) & Power & Multiple Comparisons \\
\hline AC & 132,099 & .000 & .44 & 1 & $\mathrm{CO}>\mathrm{DO}>\mathrm{CL}>\mathrm{MX}$ \\
OC & 127,385 & .000 & .43 & 1 & $\mathrm{CO}=\mathrm{DO}>\mathrm{CL}>\mathrm{MX}$ \\
POP & 86,828 & .000 & .4 & 1 & $\mathrm{CO}>\mathrm{DO}>\mathrm{CL}>\mathrm{MX}$ \\
NC & 100,430 & .000 & .39 & 1 & $\mathrm{CO}>\mathrm{DO}>\mathrm{CL}>\mathrm{MX}$ \\
PO & 82,649 & .000 & .36 & 1 & $\mathrm{CO}=\mathrm{DO}>\mathrm{CL}>\mathrm{MX}$ \\
HCMP & 77,437 & .000 & .35 & 1 & $\mathrm{CO}=\mathrm{DO}>\mathrm{CL}>\mathrm{MX}$ \\
SCO & 65,602 & .000 & .32 & 1 & $\mathrm{CO}=\mathrm{DO}>\mathrm{CL}>\mathrm{MX}$ \\
CC & 57,994 & .000 & .31 & 1 & $\mathrm{CO}>\mathrm{DO}>\mathrm{CL}>\mathrm{MX}$ \\
\hline
\end{tabular}

Table 5. Summary of the ANOVAs for the Education sector among the countries.

\begin{tabular}{cccccc}
\hline \multirow{2}{*}{ Factors } & \multicolumn{5}{c}{ Education Sector } \\
\cline { 2 - 6 } & F & Sig. & Effect Size (f) & Power & Multiple Comparisons \\
\hline NC & 56.897 & .000 & .35 & 1 & CO $=$ MX $>$ DO $>$ CL \\
PO & 123.4 & .000 & .29 & 1 & $\mathrm{CO}>\mathrm{MX}=\mathrm{DO}>\mathrm{CL}$ \\
HCMP & 66.186 & .000 & .2 & .99 & $\mathrm{CO}>\mathrm{MX}=\mathrm{DO}>\mathrm{CL}$ \\
CC & 30.329 & .000 & .19 & .99 & $\mathrm{CO}=\mathrm{MX}>\mathrm{DO}=\mathrm{CL}$ \\
POP & 40.49 & .000 & .19 & .99 & $\mathrm{CO}>\mathrm{MX}=\mathrm{DO}>\mathrm{CL}$ \\
OC & 51.498 & .000 & .16 & .99 & $\mathrm{CO}>\mathrm{MX}=\mathrm{DO}>\mathrm{CL}$ \\
AC & 33.47 & .000 & .16 & .99 & $\mathrm{CO}>\mathrm{MX}=\mathrm{DO}>\mathrm{CL}$ \\
SCO & 33.065 & .000 & .14 & .99 & $\mathrm{CO}>\mathrm{MX}=\mathrm{DO}>\mathrm{CL}$ \\
\hline
\end{tabular}


In the Education sector the best evaluations were for NC, followed by $\mathrm{PO}$ and HCMP. The lowest evaluations were for SCO, AC and OC. The effect size for $\mathrm{NC}$ and $\mathrm{PO}$ were large, and medium for the rest of the factors.

In this sector, most of the factors, PO, HCMP, POP, OC, AC and SCO, were best evaluated by $\mathrm{CO}$, followed by MX and DO, and then CL. For the other two factors, NC and CC, the evaluations by $\mathrm{CO}$ and MX were equally high and higher than those by DO, which in turn, were higher than those from CL. The evaluations for CC were the same by DO and CL.

\section{Conclusions}

\subsection{Validation of the Analytical Model}

We have found limited evidence favoring the Analytical Model proposed by CINCEL. The HCMP and the OC were the first two better predictors of the POP in the three included sectors, although the OC was more important than the HCMP in the Education sector. Therefore, the Human Capital managers in the universities should give more importance to keep the good climate of their institutions than to the HCMP.

Although it was expected that the AC would also be a good predictor of POP, this was only true in the Services and Education sectors. In the Industry sector, this factor was substituted by the NC. This result calls for the Human Capital managers in the industries to pay a greater attention to the affection of their employees and to promote their moral gratitude as a result of the benefits obtained.

The importance of the interaction of the climate and the different types of commitment as moderator variables to predict the POP was not clearly confirmed. Although significant, the interaction between OC and NC was negative in the Industry sector and positive in the Services sector. This result calls for further research.

One of the two main contributions of this research was to differentiate the effectiveness of the Analytical Model used among the different productive sectors, alerting the Human Capital managers to adapt the model to their respective productive sectors.

\subsection{Differences in the Evaluations among Countries}

The factors included in this research were evaluated very differently by the participants from the different countries and the different productive sectors. In the Industry sector Colombians and Dominicans gave the greatest importance to the human management practices and their different orientations, and the lowest importance to the commitment from continuity, but these factors were always more important for them than for Mexicans and Chileans.

To the Dominicans, the organizational performance and the normative commitment were more important than for the other nationalities, while the Colombians, followed by the Mexicans, considered the affective commitment as more important than all others. 
In the Services sector, all the factors were more important for the Colombians than for the other nationalities, except for the climate and the human management practices and their different orientations, which the Dominicans considered as important as the Colombians. Among these nationalities, the Mexicans gave the least importance to all factors.

In the Education sector, Colombians were the first again in considering the importance of all factors. The Mexicans gave the same importance to the normative and continuity commitments than the Colombians, over the Dominicans and Chileans. Dominicans gave the same importance as the Mexicans to every other factor.

More research is needed to determine the reasons for these idiosyncratic differences among the countries.

The other main contribution of this research was to establish the fact that the importance of the different factors was very diverse for each participant country. Human Capital managers should verify in each country the importance of the factors affecting performance to maximize their effectivity.

\section{References}

CINCEL [unpublished]. Estudio Transcultural sobre Clima, Compromiso y Desempeño Organizacional.

Crook, T. R., Combs, J. G., Todd, S. Y., Woehr, D. J., \& Ketchen, D. J. (2011). Does Human Capital Matter? A Meta-Analysis of the Relationship between Human Capital and Firm Performance. Journal of Applied Psychology, 96, 443-456. https://doi.org/10.1037/a0022147

Gong, Y., Law, K. S., Chang, S., \& Xin, K. R. (2009). Human Resources Management and Firm Performance: The Differential Role of Managerial Affective and Continuance Commitment. Journal of Applied Psychology, 94, 263-275. https://doi.org/10.1037/a0013116

Hofstede, G. (1997). Cultures and Organizations. Software of the Mind. New York: McGraw-Hill.

Jiang, K., Lepak, D. P., Hu, J., \& Baer, J. C. (2012). How Does Human Resource Management Influence Organizational Outcomes? A Meta-Analytic Investigation of Mediating Mechanisms. Academy of Management Journal, 55, 1264-1294. https://doi.org/10.5465/amj.2011.0088

Kehoe, R., \& Wright, P. M. (2010) The Impact of High-Performance Human Resource Practices on Employees' Attitudes and Behaviors. Journal of Management, 39, 366-391. https://doi.org/10.1177/0149206310365901

Kopelman, R. E., Brief, A. P., \& Guzzo, R. A. (1990). The Role of Climate and Culture in Productivity. In B. Schneider (Ed.), Organizational Climate and Culture (pp. 282-318). San Francisco, CA: Jossey-Bass.

Meyer, J. P., \& Allen, N. J. (1991).A Three-Component Conceptualization of Organizational Commitment. Human Resource Management Review, 1, 61-89.

https://doi.org/10.1016/1053-4822(91)90011-Z

Silvestre, E., Cruz, O., \& Sanín, A. (2016). Human Capital Practices, Organizational Climate and Commitment on Latin American Universities Performance. Invited conference in the IACBE Annual Conference and Assembly Meeting. Memphis: IACBE. 
Silvestre, E., Toro, F., \& Sanín, A. (2016). Prácticas de Gestión Humana, Clima Organizacional, Compromiso del Personal y Desempeño Organizacional Percibido en el Sector Industrial de América Latina. Ponencia invitada en la 51 Asamblea Anual de $C L A D E A$. Medellín, Colombia: CLADEA.

Silvestre, E., Toro, F., \& Sanín, A. [unpublished]. Prácticas de Gestión Humana, Clima Organizacional, Compromiso del Personal y Desempeño Organizacional Percibido en el Sector Servicios de América Latina.

Toro, F. (1992). Diseño y Validación de un Instrumento para Evaluación del Clima Organizacional. Revista Interamericana de Psicología Ocupacional, 11, 163-174.

Toro, F. (1998). Distinciones y Relaciones Entre Clima, Motivación, Satisfacción y Cultura Organizacional. Revista Interamericana de Psicología Ocupacional, 17, 27-41.

Toro, F. (2000). Clima Organizacional y Productividad Laboral. Temas de Administración, 14, 66-72.

Toro, F. (2009a). Predicción del Compromiso del Personal a Partir del Análisis del Clima Organizacional. In F. Toro (Ed.), Clima Organizacional. Una Aproximación a su Dinámica en la Empresa Latinoamericana (pp. 277-284). Medellín: Cincel.

Toro, F. (2009b). Análisis del Compromiso Organizacional En Empresas Colombianas. In F. Toro (Ed.), Clima organizacional. Una aproximación a su dinámica en la empresa latinoamericana (pp. 285-290). Medellín: Cincel.

Toro, F., Sanín, A., \& Guevara, L. (2013). Validación de una Escala para Evaluación de la Existencia, Calidad y Cobertura de las Prácticas de Gestión Humana En las Organizaciones. Revista Interamericana de Psicología Ocupacional, 32(1), 9-30. http://revista.cincel.com.co/index.php/RPO/article/view/133 